\title{
Fenomenologia e psicologia descritiva (A propósito de algumas relações entre a fenomenologia, a lógica e a matemática)
}

\author{
Carlos Morujão
}

\section{1) Os problemas iniciais}

Para Husserl, não é legítimo falar-se de qualquer tipo de «valor» sem se perguntar como é que isso, que dizemos valer, é válido. A tese é formulada, pela primeira vez, em 1891, na Filosofia da Aritmética, no decurso de uma análise do process de formação das multiplicidades, a que Husserl chama, estranhamente, "ligações colectivas», e que mais não são do que aquilo que, desde Georg Cantor, os matemáticos designam, habitualmente, pelo termo «classes» ou «conjuntos», e que ele próprio, também, designa por vezes desse modo ${ }^{1}$. Contrariando a tendência natural da consciência em voltar-se para fora (de acordo com uma definição, aliás trivial, de intencionalidade, que não dá conta, contudo, de tudo aquilo que em Husserl se liga ao emprego deste termo), o filósofo inicia um movimento de regresso à subjectividade em que se constitui o sentido daquilo que «vale». Não é que Husserl recuse, no caso vertente, a definição matemática habitual de multiplicidade, tal como, por exemplo, a do mesmo Cantor na sua Grundlage einer allgemeiner Mannigfaltigkeitslehre, aliás citada em nota de rodapé, na Filosofia da Aritmética ${ }^{2}$, de acordo com a qual podemos atribuir a duas multiplicidades diferentes a mesma extensão - ou a mesma potência - desde que nos seja possível pôr os seus membros em correspondência biunívoca, elemento por elemento. Falta-lhe, simplesmente, aquilo cuja ausência Husserl constatará também na tentativa de Frege nos

1 Para efeitos de precisão terminológica, esclareça-se que o termo husserliano para designar as classes ou os conjuntos é, em Filosofia da Aritmética, Inbegriff e não Menge; este último, começando a generalizar-se, à data, entre os matemáticos de língua alemã, tem, contudo, em Husserl, um significado diferente. Chamamos a atenção para o facto de que, ao longo deste artigo, é sempre a "multiplicidade» no sentido de Inbegriff que nos referimos, mesmo quando falarmos de Lógica Formal e Lógica Transcendental, em que é ainda à palavra portuguesa «multiplicidade» que se deveria fazer corresponder Mannigfaltigkeit, que, nesta obra, significa algo de completamente diferente de Inbegriff. No que respeita a este conjunto de termos, não é possível, ao que julgamos, encontrar uma única solução de tradução que seja válida para todas as obras de Husserl.

2 Edmund Husserl, Philosophie der Arithmetik, Erster Band, Halle-an-cer-Saale, C.E.M. Pfeffer (Robert Stricker), I891, p. 126, nota 1. 
Grundlagen der Arithmetik, a saber, uma referência à natureza dos processos psíquicos que são necessários para que se possa construir o conceito de multiplicidade ${ }^{3}$.

Haveria, assim, de acordo com Filosofia da Aritmética, que responder a um certo número de questões. 1) Qual o modo de apreensão das multiplicidades? Será necessário um acto psíquico diferente para cada um dos seus elementos, a que se acrescentaria um acto de segundo grau, que os unificaria a todos? 2) Será legítimo falar-se de uma apreensão inconsciente de alguns desses elementos? 3) Poder-se-á dizer que a representação de uma multiplicidade é uma "representação substitutiva" do somatório de cada uma das intuições isoladas dos elementos que a compõem? E como evitar, aqui, o círculo mais do que evidente e que consiste em afirmar-se que há uma representação substitutiva de objectos isolados, quando só o reconhecimento de que um objecto dado numa intuição isolada pertence já a uma multiplicidade legitima aquele tipo de representação ${ }^{4}$ ?

Estas interrogações, apesar da seriedade do esforço que traduzem para determinar o sentido objectivo das multiplicidades, não escondem, contudo, as deficiências do projecto de fundação husserliano, e mesmo um recuo da 2 . $^{\mathrm{a}}$ Parte da obra de 1891 em relação às aquisições fundamentais da 1. a, a saber, a descoberta de um tipo de visada intencional capaz de visar um «qualquer coisa qualquer» ${ }^{5}$, como abstractum de natureza formal, regulado por princípios a priori analítico-formais. É assim que, no seguimento de algumas críticas de Gottlob Frege à obra que mencionámos $^{6}$, a posição de Husserl, até 1901, ou seja, até à publicação.do $2 .^{\circ}$ tomo das Investigações Lógicas, sofrerá algumas alterações. Todas elas, porém, se consubstanciam numa mais rigorosa determinação do alcance do conceito de verdade, colhido por Husserl, em boa medida, na leitura de Bolzano, o autor da Wissenschtslehre e o defensor da existência de proposições-em-si, ou seja, de verdades independentes do facto de alguém, efectivamente, as pensar ou não. Se, por exemplo, podemos admitir que a proposição "A é verdade" equivale a "é possível que alguém julgue com evidência que A", não podemos, contudo, defender que a possibilidade ideal da experiência da evidência é redutível ao conjunto das condições naturais que possibilitam o aparecimento fáctico desta experiência ${ }^{7}$. Tal é o sentido da afirmação do $\S 51$ do $1 .^{\circ}$ tomo das Investigações Lógicas, segundo a qual a

Idem, Ibidem, p. 131.

Idem, Ibidem, pp. 219-224.

Idem, Ibidem, p. 85. Esta teoria do «qualquer coisa qualquer» necessitará, é óbvio, de ser afinada, o que Husserl não deixará de fazer na década que se seguirá à publicação de Filosofia da Aritmética, sendo os seus resultados visíveis no $2 .^{\circ}$ Tomo das Investigações Lógicas, em particular na 3. a Investigação. Husserl não pretendeu fornecer, somente, uma teoria do «objecto vago $=X »$, na linha das ontologias neo-escolásticas e da filosofia transcendental de matriz kantiana e, mais especificamente, neo-kantiana; foi objectivo de Husserl dar conta dos objectos de acordo com o seu modo de constituição específico,

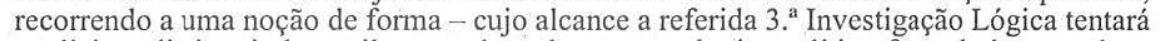
explicitar, distinguindo aquilo que releva de uma ontologia analítico-formal, do que releva de uma ontologia sintético-material, determinando esta última a «legalidade» própria dos objectos de uma dada região - a uma noção de forma, dizíamos, que não se resumia a constatar a uniformidade de um «aparecimento» reduzido ao estado de indiferenciação. (Sobre este assunto, cf. as observações decisivas de Jocelyn Benoist, in Phénoménologie, Sémantique, Ontologie. Husserl et la tradition logique autrichiènne, Paris, PUF, 1997, cap. VI, pp. 169 e segs.).

6 Acerca deste assunto, permitimo-nos remeter o leitor para o que dissemos em «Husserl e a "verdade pela forma". (Da Filosofía da Aritmética às Investigações Lógicas)», in Philosophica, 16 (2000) 47-59. 
evidência não é um sentimento capaz de nos garantir, por si só, a verdade de um certo juízo. Posteriormente, nos $\S \S 59$ a 61 de Lógica Formal e Lógica Transcendental $^{8}$, em jeito quase kantiano, Husserl salientará os laços de solidariedade que ligam a noção de evidência à possibilidade da reprodução e da síntese do reconhecimento. A evidência é solidária da capacidade de reiterar (de acordo com modalidades que são, obviamente, diferentes conforme se trate de objectos reais ou de objectos ideais) uma certa experiência, na qual algo foi dado originariamente, e também da possibilidade de provar que pensamos ainda na mesma coisa em que pensávamos no momento precedente. E como, por outro lado, todas as nossas representações se formam pouco a pouco, a representação completa, pela qual obtemos a evidência da unidade de uma multiplicidade, deve encontrar-se no seguimento do acto pelo qual ela foi sendo produzida, pois, a não ser assim, estaríamos, de cada vez, na presença de uma representação nova. Ora, é nesta possibilidade de um objecto ou de um estado-de-coisas, enquanto correlatos de um acto intencional, serem identificados sempre da mesma forma, que se realiza a estrutura teleológica universal da consciência.

Husserl pensa aqui a verdade a partir da concepção tradicional de adaequatio. A verdade mais não é do que a ideia de um certo acordo entre o que, na 1. " «Investigação Lógica», se chama uma intenção signitiva e o seu preenchimento intuitivo, graças à presença na consciência do estado-de-coisas visado. Mas, além disso, deve ser possível fazer uma experiência desse acordo, que seja em tudo semelhante à que acontece num acto perceptivo normal. Um juízo verdadeiro equivale, para Husserl, à visão de um estado ideal de coisas ${ }^{9}$. Esta tese tem pesadas consequências para todo o desenvolvimento futuro da fenomenologia, e talvez mesmo sem ela a fenomenologia não se tornasse naquilo que efectivamente foi e que dela viemos a conhecer. Encontram-se aqui as raízes do seu tão discutido intuicionismo. Para o bem e para o mal, foi esta a herança de Franz Brentano, bem mais importante, em nosso entender, do que a que se exprime, por exemplo, na adopção, por Husserl, do termo «intencionalidade», ou no reconhecimento da importância da tese sobre a «inexistência» intencional dos objectos, como característica da região dos actos psíquicos.

O intuicionismo de Brentano, recordemo-lo, encontra-se, antes de mais, na sua teoria do juízo, que Brentano procura reconduzir ao plano perceptivo ao afirmar que em «S é p» está implicitamente contida a afirmação de que «S é» ${ }^{10}$. Neste sentido, e na medida em que é herdeira desta tese de Brentano, a concepção husserliana de intuição é bem diferente da de Kant, sendo perfeitamente defensável a tese de Eugen Fink, no seu célebre artigo nos Kant-Studien em 1933, ao recusar qualquer inconsequência no pensamento husserliano quando este, defendendo o privilégio da intuição, não a considera, à maneira de Kant, como o primeiro momento de um processo que culminaria na síntese do juízo" ${ }^{11}$ E é, de facto, de Brentano que a concepção de intuição em Husserl é a herdeira. Se em «S é p», existe, em primeiro

7 Uma excelente análise desta questão em Günther Patzig, "Husserl on truth and evidence", in J. N. Mohanty, Readings on Edmund Husserl's Logical Investigations, The Hague, Matinus Nijhoff, 1977, pp. 179-196, p. 181.

8 Husserl, Formale und transzendentale Logik, in Husserliana, Band XVII, pp. 165-173.

9 Günther Patzig, op. cit., p. 192.

10 Cf. Franz Brentano, Die Lehre vom richtigen Urteil, Bern, Francke Verlag, 1956, § 30, pp. 113-121.

11 Aqui, mais não fazemos do que indicar todo um conjunto de problemas, tão interessantes quanto complexos, mas cujo tratamento exaustivo ultrapassa, de longe, os limites que 
lugar, um «S é», e se, sem este, não veríamos «S» como «p» (pois não teríamos visto «S», pura e simplesmente), nada mais natural do que interrogar os fundamentos do que se poderia chamar a gramática do «é», quer dizer, o fundamento da multiplicidade dos seus empregos legítimos. Aqui, a audácia de Husserl é enorme: num enunciado do tipo «S é p» todos os momentos são preenchidos intuitivamente, e nenhum é preenchido mais ou menos do que qualquer um dos outros. No caso contrário, não nos encontraríamos diante de um enunciado legítimo, ou seja, dirigido ao preenchimento dos interesses de natureza cognitiva.

Se bem ajuizamos, sem o peso desta herança não entenderíamos também que, no $\S 3$ de Ideias I, Husserl possa ter defendido o carácter simultaneamente ideal e objectivo das eide, como algo a que se dirige uma visada intencional e que nela se dá «em si mesmo», ou, dito de outro modo, como «objecto» no sentido necessariamente lato da lógica formal. É ainda ela que sustenta a analogia de tipo particular que Husserl estabelece entre a percepção das coisas, num mundo-de-coisas cujo sentido escapa à atitude ingénua da consciência natural, e a visão das idealidades lógico-matemáticas ${ }^{12}$, que tem por base esse mesmo mundo, uma vez fenomenologicamente reduzido.

Assim, desde, pelo menos, o semestre de Inverno de 1906-07, como testemunha o conjunto de lições intituladas Introdução à Lógica e à Teoria do Conhecimento $^{13}$, que Husserl, apesar de reconhecer o fracasso do seu projecto fundacional, tal como se formulara na Filosofia da Aritmética, regressa ao seu problema inicial, reconhecendo que na ciência, enquanto conjunto de proposições ligadas num todo sistematicamente fundamentado, o sentido de muitas proposições é determinado pela subjectividade. Adivinha-se, aqui, que alguém pudesse defender a tese seguinte: se se diz que, em ciência, se usa o pensamento, necessariamente, de uma certa forma, tendo em vista a obtenção da verdade, não se estará ainda a falar de pensamento e, nessa medida, de um caso especial do seu simples uso? Só que, a ser assim, ignorar-se-ia ainda o valor do pensamento, ou seja, o seu carácter objectivo, de que nenhuma ciência de factos, como, por exemplo, a psicologia

nos impusemos nestas páginas. É claro que o que haveria a discutir é se a intuição inclui já esse momento de conhecimento que tanto Husserl como Brentano lá querem ver, ou se não estaremos, antes, diante de uma petição de princípio: é porque já lá pusemos indevidamente esse momento que depois julgamos, com toda a naturalidade, tê-lo lá encontrado. $\mathrm{O}$ «Schlusswort» a Lógica Formal e Lógica Transcendental (Formale und transzendentale Logik, ed. cit., pp. 296-298) parece-nos confirmar esta tese: uma "estética transcendental», enquanto doutrina de um mundo possivel de experiência pura, anterior a todas as actividades de natureza categorial, deverá, diz Husserl, explicitar o modo de surgimento de «einheitliche Objekte», sobre os quais se edificarão as realizações lógicas de nível superior. Mas não será a unidade, justamente, a primeira determinação categorial dos objectos, aquela sem a qual um objecto não é um objecto, distinto de outros objectos? Por outras palavras, não será a fenomenologia a constante subrepção de processos de idealização em níveis onde, supostamente, eles deveriam estar ausentes? Sobre este assunto cf. Jocelyn Benoist, L'a priori conceptuel. Bolzano, Husserl, Schlick, Paris, Vrin, 1999, pp. $59-80$.

12 Que se trate de «idealidades» e que, por conseguinte, a lógica não séja, somente, uma disciplina de ordem prática, é aquilo de que Husserl se dará conta após a redacção do seu Habilitationsschrift, de 1887, Sobre o Conceito de Número. Por outro lado, reconhecendo as origens lógicas da aritmética, Husserl reconhecerá também a impossibilidade de levar a cabo um projecto fundacional exclusivamente intra-matemático, ao contrário do que defendera o seu mestre Weiertrass.

13 Husserl, Eileitung in die Logik und Erkenntnistheorie (1906-1907), Husserliana, Band XXIV, Den Haag, Martinus Nijhoff, 1984. 
científica, pode decidir. Husserl poderá então reconhecer tudo o que havia de inadequado na tese que defendera na Filosofia da Aritmética - a saber, a redução da lógica a um mero sistema de sinais, capaz de exprimir simbolicamente certo tipo de relações entre conceitos de número não «dados» numa intuição -, e, ao mesmo tempo, reconhecer que o estabelecimento do conjunto das disciplinas formais (e, em primeiro lugar, da própria ontologia formal) nas quais repousa toda a actividade da ciência, exige uma clarificação da natureza dos actos intencionais em que tais disciplinas se originam.

O que está aqui em causa é uma conexão de fundação entre os actos psíquicos realizados, de forma que este recurso à subjectividade não é incompatível com, antes exige, que seja posta de lado qualquer referência a uma individualidade determinada, uma vez que a conexão que se tem em vista é válida para todos os seres racionais. Husserl dá-nos um exemplo esclarecedor: se pensarmos num jogo de dados, em que cada dado tem cinco faces em branco e uma com um ponto, a probabilidade de, em cada jogada, sair uma face em branco é maior do que a de sair uma face com um ponto; ora isto é verdadeiro tanto para um homem como para um anjo, quer dizer, para uma outra qualquer criatura racional que jogasse o mesmo jogo nas mesmas condições.

O mesmo acontece, por exemplo, no tipo de raciocínio que é conhecido pelos lógicos sob a designação de modus ponens: $[(\mathrm{p} \rightarrow \mathrm{q}) \wedge \mathrm{p}] \rightarrow \mathrm{q}$. Estabelece-se uma conexão entre dois actos psíquicos, de que resulta um terceiro acto, conexão essa que está fundada na essência dos actos. Há aqui uma síntese: é nela que se funda a evidência lógica, que permite distribuir valores de verdade e dizer, por exemplo, que a proposição, que escrevemos acima com os símbolos do chamado «cálculo proposicional», é verdadeira para qualquer valor de verdade de 'p' e de 'q', ou seja, é uma tautologia. A lógica repara nessa evidência, mas não interroga o seu fundamento, ou seja, a subjectividade em que ela se gera. Compartilha assim, com as chamadas ciências mundanas, seja qual for o grau de tecnicidade dos seus procedimentos formais, o destino de ser uma "ingenuidade de grau superior", de acordo com uma expressão de Lógica Formal e Lógica Transcendental.

\section{2) A «região» consciência}

A consciência, para Husserl, como todos sabemos, não é uma região do mundo. Para entendermos esta afirmação, temos de entender que Husserl fala de consciência transcendental, ou seja, de uma consciência para a qual o mundo aparece como uma «transcendência» que ela própria encerra de modo «irreal», e não de consciência empírica ou psicológica, que, esta sim, é uma região do mundo e constitui o tema próprio de uma ciência mundana, a saber, a psicologia. Por outro lado, esta consciência transcendental, que só o é na medida em que começou por suspender a tese do mundo, ou seja, a crença ingénua na sua existência e no seu modo de ser, tal como nos é dado pelas várias ciências mundanas - ou ciências da atitude natural -, esta consciência, dizíamos, deve poder «pôr» o mundo originariamente, ou seja, liberto de todas as idealizações e de todas as camadas de sentido já constituídas.

O regresso em força da problemática da consciência, já o demos a entender, é anunciado, com grande firmeza, mas não sem alguns equívocos, na «Introdução» ao $2^{\circ}{ }^{\circ}$ tomo das Investigações Lógicas. Falando, surpreendentemente, de uma fundação psicológica da lógica pura, tese cuja validade todo o 1. ${ }^{a}$ tomo, os «Prolegómenos a uma Lógica Pura», parecia ter-se encarregado de refutar, Husserl defende o seu 
carácter rigorosamente descritivo, acrescentando que uma mesma esfera de descrições puras pode servir de preparação a ciências teóricas diferentes, cuja independência, por conseguinte, não se veria, assim, posta em causa. Não seria, então, tanto à psicologia enquanto ciência, como a certas classes de descrições que, relativamente à própria psicologia, assumem um carácter preliminar, permitindo-lhe, posteriormente, o estabelecimento de relações genéticas entre os factos psíquicos, que o lógico ficaria a dever a sua compreensão da base daquelas abstracções fundamentais nas quais reconhece, com evidência, a essência dos seus objectos ${ }^{14}$.

Aparentemente, a mesma tese é retomada no $\S 14$ das Meditações Cartesianas, mas, em nosso entender, com uma diferença fundamental que, por contraste, nos permite compreender melhor o alcance da tese da «Introdução» ao $2 .^{\circ}$ tomo das Investigações Lógicas e o modo como todo o desenvolvimento futuro da fenomenologia se apoia numa interpretação determinada dela. Ao defender, na obra de 1929, o paralelismo estrito entre a fenomenologia transcendental e a psicologia descritiva, Husserl sublinha que a primeira implica a observância da redução transcendental e, por conseguinte, a compreensão do sentido do mundo como «mundo reduzido», ao passo que a segunda, ciência da atitude natural, resulta de uma limitação por abstracção das investigações de carácter antropológico, confinadas ao estudo da região "vida psíquica». Encontramo-nos, assim, diante de uma tese metafisica determinada, a saber, a que privilegia o carácter absoluto de ser da consciência reduzida, e já não diante daquela «neutralidade» metafísica que as Investigações Lógicas exigiam como condição para uma análise fenomenológica dos actos constituintes. Esta «neutralidade», por seu lado, assegurada (pelo menos quanto às suas intenções) pelo carácter descritivo da psicologia, permitindo suspender qualquer tese de carácter ontológico sobre o modo-de-ser da consciência cujas vivências intencionais se trata de descrever, será talvez a marca de uma radicalidade (traindo mais uma vez a herança de Brentano) que poderia eventualmente, se Husserl se lhe tivesse mantido fiel até ao fim, ter conduzido a fenomenologia a outras paragens. É que uma psicologia que se confinasse a um programa rigorosamente descritivo, mais do que deixar indeterminado o estatuto da psyché, ou do que deixar por interrogar o seu estatuto no De Anima de Aristóteles ${ }^{15}$ - em cuja dependência se encontram todas as teses metafísicas sobre a sua natureza, até Husserl inclusive -, levaria, muito provavelmente, a pôr em causa a necessidade de admitir a existência de qualquer coisa como uma psyché, bem como a legitimidade de uma distinção entre o "psíquico» e o "físico». A evolução efectiva da fenomenologia husserliana conduziu-a, obviamente, a interrogar de um certo ponto de vista aquela legitimidade, ou seja, a legitimá-la por meio de uma descrição rigorosa dos dados imanentes de uma consciência transcendentalmente reduzida.

Esta noção de consciência, de que a fenomenologia será então a ciência, difere substancialmente das de Descartes e de Kant. A consciência de Descartes, sublinha Husserl, é ainda uma região do mundo, patente, aliás, no emprego do termo res para a designar, pelo que interessará a Descartes, mais do que transformá-la em campo privilegiado de análises fenomenológicas, explicar a sua origem ôntica. A consciência de Kant, pelo seu lado, é o suporte do valor objectivo do conhecimento das ciências mundanas, tal como o deixa claro a "Analítica dos Princípios" da Crítica da Razão Pura, em particular as secções sobre as "Antecipações da Percepção" e as

14 Idem, Logische Untersuchungen, Zweiter Teil, in Husserliana, Band XIX/1, p. 24.

is Aristóteles, De Anima, III, 8, 431 b 12 e segs. 
“Analogias da Experiência", e, como tal, supõe um mundo já constituído; não poderá, por conseguinte, como em Husserl, ser a sua origem.

Mas, uma vez suspensa a tese do mundo, a consciência não se limita a afirmar o seu ser próprio, pois aquela suspensão é ainda acompanhada da afirmação da presença do mundo na consciência, agora como «mundo reduzido», fenómeno puro, ou cogitatio. Tratar-se-á, então, de descobrir as modalidades originárias da sua apreensão, da relação originária da consciência com ele, na qual ele é constituído no seu sentido de «mundo». Só assim, aliás, se entendem as críticas, dirigidas no início de A Filosofia como Ciência de Rigor, tanto ao naturalismo como ao historicismo. Não é somente o «reducionismo» de uma posição filosófica para a qual tudo é físico, ou tudo é psíquico, que está em causa, mas sim, bem mais radicalmente, uma indagação acerca da natureza do próprio mundo, que legitime por que motivo pode ser «dividido» deste modo ${ }^{16}$.

A consequência fundamental do naturalismo é a naturalização da consciência e dos seus dados intencionais imanentes, cuja corolário é uma interpretação, igualmente naturalista, dos princípios lógico-formais. Poderá alguma vez o naturalismo, pergunta Husserl, constituir uma ciência normativa? Poderão as normas apoiar-se em factos, ou seja, em processos psíquicos, tal como são descritos por uma psicologia naturalista? Mas não sendo a forma lógica um momento do objecto, ela dirá respeito ao "qualquer coisa em geral", como sua determinação primeira, não podendo ser abstraída do objecto por um processo de generalização que tivesse o seu ponto de partida em características que fossem comuns a todas eles. A generalização poderá apenas determinar os princípios eidéticos a que obedecem necessariamente os objectos de uma dada região - a dos objectos no espaço, a dos seres vivos, a dos seres dotados de inteligência, etc. - e constituir, a partir deles, diversas ontologias regionais, mas nunca poderá servir para a constituição de uma lógica pura, base para o estabelecimento de uma ontologia formal do «objecto qualquer». E se a forma lógica fosse um momento do objecto, ela seria uma espécie de género comum. Ora, uma das teses principais de Husserl diz respeito à sua transeendêneia relativamente a qualquer género.

Precisamos de ver melhor, então, qual o tipo de legalidade que lhe é própria e por que motivo não pode ser regulada pela psicologia. É que esta, sendo uma ciência mundana, tem por função explicar de que modo os estados psíquicos se encadeiam. Se é possível estabelecer uma relação causal entre os fenómenos psíquicos e os estados físicos e químicos do cérebro que estão na sua origem, não é possível estabelecer tal relação entre os fenómenos psíquicos e os princípios lógicos. O real não pode ser a causa do «ideal». Ora, neste sentido, o psicologismo de Filosofia da Aritmética assumia já um carácter sui generis, bem diferente daquele que o 1. ${ }^{\circ}$ Tomo das Investigações Lógicas tomou como seu alvo. Toda a análise da génese da numeração - ou seja, do número cardinal - está aí para comprová-lo. Se Husserl recusa que os números sejam conceitos de relação fundados sobre a equivalência entre classes, é para melhor evidenciar que o interesse que conduz a destacar a forma geral da multiplicidade ou da numeração se funda já num uso habitual do pensar, em que os objectos são considerados independentemente do facto de serem intrinsecamente constituídos desta ou daquela maneira ${ }^{17}$.

Além disso, o facto de em Filosofia da Aritmética não estar ainda presente o tema da redução - tematizado, pela primeira vez, em A Ideia de Fenomenologia,

17 Idem, Philosophie der Arithmetik, ed. cit., pp. 126 e segs. 
mas já anunciado, contudo, em algumas passagens do $2 .^{\circ}$ Tomo das Investigações Lógicas - é, para nós, tanto mais interessante quanto nos permite evidenciar um fio condutor de toda a meditação husserliana que nem sempre tem tido, quanto a nós, a atenção que mereceria da parte dos comentadores. É necessário, sem dúvida, salientar que o fracasso do projecto de Filosofia da Aritmética conduziu às críticas ao psicologismo que culminam no $1 .^{\circ}$ Tomo das Investigações Lógicas; não menos necessário é destacar que o «regresso» à subjectividade, que marca a «viragem». transcendental da fenomenologia, se distingue fortemente da fase inicial do pensamento husserliano pela presença do tema da redução, com a consequente transformação da fenomenologia em ciência absoluta de uma região de ser absoluto; não menos importante é destacar a presença do tema da intuição, ou seja, na linguagem de Husserl a partir de Ideias $I$, da doação originária, em carne e osso, da "coisa mesma», paralela ao distanciamento, já anunciado em Filosofia como Ciência de Rigor, em relação aos processos indirectamente simbólicos da matemática, que somente com o auxílio de um complicado aparelho dedutivo e demonstrativo se consegue assegurar das suas verdades ${ }^{18}$; tudo isto, porém, não só não esgota, em nosso entender, o significado do idealismo husserliano como filosofia da subjectividade transcendental, como oculta mesmo uma das suas dimensões fundamentais, a saber, aquela que, não pondo em causa o primado da evidência, se interroga, justamente, sobre o modo como as evidências se articulam em sistema. A este, só estranhará a que chamemos axiomático ${ }^{19}$ quem se esquecer que, para Husserl, a realização do interesse orientado para o conhecimento supõe a satisfação de duas condições prévias: em primeiro lugar, uma clarificação completa do problema das formas da significação (que subjazem a todos os tipos de juízos possíveis), e, em segundo lugar, a inventariação completa das leis que operam no interior das categorias de significação, anteriores a uma sua qualquer especificação material, e que é sobre elas que se deverá edificar uma doutrina das relações formais entre objectos e entre estados-de-coisas.

É que à fenomenologia parece não bastar assegurar-se do seu tema próprio, a saber, a consciência e as suas vivências intencionais, nem do método que permitirá transformar essa mesma consciência num campo de análises fenomenológicas concretas. Se o recurso à intuição, à visão da "coisa mesma» em "carne e osso», lhe proporciona o acesso a um domínio de evidências, não será igualmente necessário, e isto em nome da sua cientificidade, sempre reclamada por Husserl,

18 Idem, Philosophie als strenge Wissenschaft, ed. cit., pp. 61-62: «Pelo facto de nas ciências mais impressivas dos tempos modernos, as ciências físico-matemáticas, a maior parte do trabalho exterior se processar segundo métodos indirectos, estamos demasiado inclinados a sobrevalorizar os métodos indirectos e a desconhecer o valor das captações directas. [...] o maior passo que o nosso tempo deve dar é o de reconhecer que, com a intuição filosófica em sentido correcto, a intuição fenomenológica das essências, se abre um campo infinito de trabalho e uma ciência que, sem todos os métodos indirectos simbolizantes e matematizantes, [...] obtém uma grande quantidade de conhecimentos rigorosos»).

19 Tomamos este termo no sentido de Hilbert, de que Husserl, como se sabe, se reclamará nos $§ \S 28$ e segs. de Lógica Formal e Lógica Transcendental. O programa de Hilbert foi seriamente abalado, no que respeita às suas pretensões, pela demonstração, por Kurt Gödel, da existência, em qualquer sistema axiomático, de unentscheidbarer Sätze, quer dizer, de proposições que, embora sendo formuláveis nos conceitos prescritos pelo sistema, não podem ser, contudo, demonstradas no seu interior. Diremos na 3. a secção deste trabalho por que motivo o chamado «teorema de Gödel» não nos parece pôr em causa o que poderíamos chamar as pretensões axiomáticas de Husserl. 
mostrar como essas evidências se organizam? Esta multiplicidade de evidências, que o fenomenólogo arranca ao fluxo heraclitiano da vida da consciência, não se organizará num sistema de relações de que será possível, em todo o caso, descobrir o modelo invariante ${ }^{20}$ ? Será a corrente da consciência, segundo as próprias palavras de Husserl em Ideias I, uma multiplicidade em sentido matemático e, nas suas aplicações factuais, uma multiplicidade definida concreta ${ }^{21}$, à maneira da física? Será a um esclarecimento deste problema que dedicaremos a próxima secção deste trabalho.

\section{3) Unidade e multiplicidade}

É sabido que nas Lições para uma Fenomenologia da Consciência Interna do Tempo Husserl distingue a percepção de uma duração, da duração da própria percepção. Esta distinção permite afirmar que, se suspendermos todas as transcendências, a percepção, de acordo com os seus constituintes fenomenológicos, conserva ainda a sua temporalidade própria. É assim que, no célebre exemplo da melodia, o som que agora soa expulsa do presente vivo da consciência o som que soava há instantes, tal como se antecipa aos que virão a soar nos instantes seguintes. $\mathrm{O}$ mesmo acontece com um som isolado, que também dura. Mas tanto neste segundo caso como no primeiro há uma totalidade que é visada e dura em cada uma das suas fases, tal como podemos afirmar que cada número da série dos inteiros verifica as propriedades gerais do número ${ }^{22}$.

Assim, o tema que enunciámos no final da secção anterior não constituía uma novidade em 1913, nem, muito menos, caracteriza uma etapa tardia do desenvolvimento do pensamento husserliano. Já em 1894 os Psychologischen Studien zur elementaren Logik descreviam o campo da consciência como uma globalidade em que tudo está em conexão com tudo, mas, desde logo, ao estabelecer uma distinção entre conteúdos independentes e conteúdos dependentes, evidenciando o que a separa das multiplicidades em sentido matemático ${ }^{23}$. É que estas, enquanto "ligações colectivas" no sentido que Filosofia da Aritmética atribuía a esta expressão, supõem uma independência entre os elementos que as

20 Cf. Jacques English, "La phénoménologie est-elle axiomatisable?», J.-F. Courtine (ed.), Phénoménologie et Logique, Paris, Presses de L’École Normal Supérieur, 1996, pp. 83-107 , p. 88.

21 Em nota ao $§ 72$ de Ideias I (Hua, Band III/1, p. 153) Husserl aproxima a noção de "definido» da noção de "completude», tal como Hilbert a emprega, no sentido em que se pode dizer, de um sistema axiomático, que, partindo dos axiomas, é possível demonstrar todas as suas fórmulas válidas. Em 1929, Lógica Formal e Lógica Transcendental chamará à Definitheit a «ideia de uma forma», no interior da qual todas as proposições lógico-gramaticalmente correctas decorrem analiticamente, ou seja, de modo puramente dedutivo, dos axiomas. (Formale und Transzendentale Logik, §30, ed. cit., p. 100).

Cf. Husserl, Vorlesungen zur Phänomenologie des inneren Zeitbewusstseins, in Husserliana, Band X, p. 24, $\S 8$. Uma nota dos editores da Husserliana esclarece que este texto se baseia num esboço datado de 10-13 de Novembro de 1911.

23 Idem, Psychologische Studien zur elementaren Logik, in Husserliana, Band XXII, pp. 92-123. Cf. § 1, p. 92: «Das jeweilige Gesamtbewusstsein ist eine Einheit, in der alles mit allem in Verbindung steht. Es finden sich jedoch in der weise der Verbindung, in ihrer relativen Festigkeit, in ihrer Mittelbarkeit oder Unmittelbarkeit erhebliche Unterschiede. Auf solche Unterschiede Bezieht sich auch die hier zu betrachtende Einteilung der Inhalte in selbständige [...] und unselbständige [...]».

24 Idem, Formale und transzendentale Logik, § 24, p. 82. 
constituem - considerados apenas na sua generalidade formal, com a exclusão de qualquer determinação de conteúdo ${ }^{24}$-, elementos cuja unidade se fica somente a dever ao acto psíquico que os coligiu, ao passo que a dependência entre certos conteúdos psíquicos - por exemplo, entre um som e a sua intensidade - se funda na própria natureza do conteúdo. Sem que, no entanto, como salienta Husserl nos já citados Psychologische Studien, seja imediatamente evidente em que é que consiste a necessidade desta dependência, tanto mais que não a podemos pensar como tendo um carácter causal ${ }^{25}$. Por outro lado, é óbvio que um certo tipo de independência entre conteúdos psíquicos, como aquele que se verifica, por exemplo, entre a representação da cabeça de um cavalo, que destacamos do resto do corpo, e a representação desse mesmo corpo, não nos explica se a relação de uma multiplicidade em sentido matemático com a totalidade dos seus elementos é semelhante à que se verifica neste caso, na medida em que foi somente por meio da fantasia que realizámos esta última operação.

Isto não impedirá, contudo, que a «região» consciência possa ser pensada como uma multiplicidade e, no sentido que Lógica Formal e Lógica Transcendental atribui a esta expressão, uma «universalidade formal vazia», quer dizer, constituída por um conjunto de proposições - onde se exprime a totalidade das suas evidências, adequadas ou não - regulado por uma forma e subordinado aos princípios de não-contradição e do $3 .^{\circ}$ excluído, capazes de proporcionar ao domínio em questão o carácter de uma ciência dedutiva. Acerca das condições que permitem uma tal formalização, Husserl é especialmente claro. Se, para se realizar, ela exige um «esvaziamento ${ }^{26}$ dos conteúdos, tal esvaziamento não se confunde com a generalização enquanto subida a um género superior e de maior universalidade, mas equivale ao processo pelo qual o pensar relaciona de modo análogo aquilo que é diferente, tal como na «teoria das proporções» do Livro V dos Elementos de Geometria de Euclides $^{27}$.

Com que ficamos, uma vez realizado aquele esvaziamento? Com a evidência de que um juízo qualquer, se o supusermos adequado ao estado-de-coisas que nele é julgado, exclui a priori a possibilidade da verdade do seu contraditório; e de que a adequação, positiva ou negativa, do juízo em causa, ao estado-de-coisas por ele visado, numa sintese de "preenchimento», exclui, por motivos igualmente a priori, a possibilidade da sua falsidade.O sentido destas afirmações é, segundo nos parece, bastante claro: embora em si mesmos os princípios de não-contradição e do $3 .^{\circ}$ excluído não comportem nenhuma referência ao problema da evidência, limitando-se a estabelecer a impossibilidade de atribuirmos o mesmo valor de verdade a dois juízos contraditórios (ou valores de verdade diferentes, em simultâneo, ao mesmo

25 Idem, Psychologische Studien zur elementaren Logik, ed. cit., pp. 93-94. É justamente aqui que começamos a entender a importância do modelo fornecido por aquele tipo de dependência existente entre proposições, no interior de um sistema axiomático.

26 Acerca do «esvaziamento» (Entleerung), cf. Ibidem, p. 97, n. 1.

27 Husserl critica com razão as insuficiências da teoria aristotélica da abstracção para pensar tudo aquilo que se indica com o termo Entleerung. Contudo, não queremos deixar de chamar a atenção para uma passagem dos Segundos Analíticos, I, 5, 74 a, 17-25, em que Aristóteles, de forma surpreendente, se refere ao princípio de convertibilidade das proporções, trate-se de números, rectas, corpos ou tempos, que permite uma prova universal para domínios diferentes. As proporções, tal como outras formas de relação, não tendo a autonomia dos objectos metafísicos, que permitiria a constituição de uma ontologia regional qualquer, encontram-se na base de uma mathesis universalis. (Sobre isto, cf. Oskar Becker, Grösse und Grenze der mathematischen Denkweise, Freiburg/ /München, Karl Alber Verlag, s/d, pp. 88-89. 
juízo), que sentido teria afirmá-lo independentemente da referência à possibilidade do seu preenchimento intuitivo? Ou seja, sem a referência àqueles actos subjectivos capazes de proporcionar a evidência, positiva ou negativa, de um determinado estado-de-coisas? Como garantir, sem o recurso a uma intuição possível - de que o lógico no seu cálculo pode, contudo, prescindir -, que a proposição «é verdade que p» exclui a sua contraditória? Husserl afirma:

«O duplo princípio de contradição e do terceiro excluído diz simplesmente que um juízo é uma destas duas coisas, verdadeiro ou falso. Ele não contém nenhuma palavra subjectiva do género da evidência, apesar da verdade e da falsidade, originariamente, extraírem da evidência o seu sentido e a sua legitimidade. Um juizo não é uma vez verdadeiro e outra vez falso, mas sim verdadeiro ou falso de uma vez por todas; quer dizer, quando ele é uma vez evidente, legitimado uma vez na evidência de uma adequação de preenchimento, não pode, de uma outra vez, ser legitimado como falso na evidência de uma "adequação de desengano" ${ }^{28}$.

O problema é, então, este: como integrar todo aquele conjunto de verdades que nos são familiares na medida em que operamos com elas, mas cuja natureza na realidade desconhecemos - já Hegel afirmava no «Prefácio» à Fenomenologia do Espirito: «das bekannt überhaupt ist darum, weil es bekannt ist, nicht erkannt $»^{29}-$, como integrá-las, então, num sistema de definições e de teoremas em que a totalidade das operações intencionais que as suportam recebe um fundamento a priori? Husserl começou por fornecer um esboço de realização deste programa no capítulo $2 .^{\circ}$ da $3 .^{\text {a }}$ "Investigação Lógica». Ao afirmarmos que um certo "a" se encontra numa relação compreensiva com um certo "m", de tal modo que "a" é fundado por "m" e não pode aparecer sem ele, comprometemo-nos a afirmar que " $\mathrm{a}_{0 \text { " }}$ ou " $\mathrm{m}_{0 \text { ", }}$, enquanto especificações ou casos particulares de "a" e de "m", respectivamente, se encontram numa idêntica relação compreensiva de fundamentação. Se pensarmos em "a" como parte de " $m$ ", poderemos prosseguir a nossa análise determinando que tipo de relações tem "a" com as restantes partes de "m", que poderão igualmente ser de fundamentação ou não; e, no caso de o serem, de fundamentação bilateral ou unilateral, imediata ou mediata.

Já no $\S 13$ da $3 .^{\mathrm{a}}$ «Investigação», ao encerrar o capítulo $1 .^{\circ}$, Husserl apresentara alguns exemplos de tais relações de dependência, e da máxima importância para o exame da questão que nos ocupa. Com efeito, Husserl observara que um momento de tempo não é independente de outro momento de tempo, que o antecedeu ou que lhe sucederá, na medida em que se integra num fluxo; mas, ao invés, as porções do espaço que entram no campo visual e são actualmente objecto de percepção são separáveis do continuum espacial a que pertencem e constituem, por conseguinte, relativamente a ele, momentos independentes. $\mathrm{O}$ espaço não é um fluxo temporal, como todos sabemos por experiência imediata. E, no entanto, só o saberemos realmente - seja-nos permitido, insistir, uma vez mais, neste ponto -, a partir do momento em que as leis de essência aqui enunciadas sejam efectivamente

28 Husserl, Formale und transzendentale Logik, § 77, ed. cit., pp. 201-202. Como Husserl explicará um pouco mais adiante, no $\S 79$, o princípio do $30^{\circ}$ excluído assegura somente a decidibilidade de direito, e não de facto, de todos os juízos.

29 Hegel, Phänomenologie des Geistes, in Werke (herausgegeben von Eva Moldenhauer und Karl Mårkus Michel), Frankfurt am Main, Suhrkamp, 1986, Band 3, p. 35. 
demonstradas, quer dizer, integradas num sistema teórico dedutivo, onde se cumpra, finalmente, aquela exigência fenomenológica de «ver» surgir o objecto numa intuição doadora originária ${ }^{30}$.

Todas estas afirmações, se, por um lado, parecem suficientes para comprovar a tese que defendemos, não deixam, por outro, se comparadas com outras, de pôr em evidência as reservas husserlianas perante a possibilidade de realizar um tal projecto axiomático. E isto por certas razões de princípio, que nada parece ficarem a dever à suspeita da existência de unentscheidbarer Sätze, no sentido de Kurt Gödel. Para Husserl, ao contrário do que defendia Hilbert, ou, pelo menos, ao contrário daquilo que Hilbert esperava realizar, mas por razões que não coincidem, de forma alguma, com as de Gödel, um sistema axiomático não se pode fechar «por dentro». Para o perceber, vejamos o que nos dizem, sobre esta questão, os $\S \S 72$ a 75 de Ideias I. Começando por defender que a multiplicidade das figuras espaciais é uma «multiplicidade matemática em sentido estrito», e que a geometria, por isso mesmo, pode estar completamente segura de determinar todas as possibilidades de aparecimento de uma figura (pois em cada uma delas revela-se, de um determinado modo, a essência pura do espaço), Husserl afirma que uma disciplina dedutiva, que defina exaustivamente e de forma puramente analítica uma multiplicidade, se pode chamar um «sistema definido de axiomas»" ${ }^{31}$. Mas interroga-se: sendo a fenomenologia uma disciplina eidético-concreta, será possível, apesar de as essências das vivências que constituem o seu campo temático possuírem grande quantidade de notas abstractas, abordar os géneros supremos correspondentes a estas notas abstractas como se de disciplinas «definidas» ou «matemáticas» se tratasse? Por outras palavras: não haverá conceitos que são essencialmente, e não apenas acidentalmente, inexactos e, por isso mesmo, não-matemáticos?

Mas se há, tal ficar-se-á a dever à natureza própria daquilo de que eles são os conceitos, ou seja, ao seu modo de doação, que a fenomenologia, desde o primeiro momento da sua formulação com as Investigações Lógicas, mas já no que poderíamos chamar a sua "pré-história», a saber, essa década decisiva para o desenvolvimento do projecto fenomenológico que foram os anos 1891-1900, se comprometeu a respeitar, num gesto em que se decidia, se é que assim podemos dizer, pela sua própria possibilidade. É que o «valor» desses conceitos, ou dessas idealidades, não se gerando na consciência psicológica e não dependendo de processos psíquicos efectivos, também não tem sentido fora do seu aparecimento possível a uma consciência ${ }^{32}$. E se a fenomenologia é possível é porque, pelo seu lado, se comprometeu também a respeitar esta última possibilidade.

30 Robert Sokolowski salientou correctamente a especificidade da noção husserliana de «originário», mostrando que se refere ao modo de o objecto em análise ser trazido ao seu modo próprio de estar presente, quer dizer, de se diferenciar de todos os outros. Neste sentido, a intuição (na acepção deste termo no $§ 24$ de Ideias $I$ ) e a dedução não se contrapõem forçosamente. (Cf. Robert Sokolowski, «Logic and Mathmatics in Husserl's "Formal and Transcendental Logic"», in David Carr and Edward S. Casey (ed.), Explorations in Phenomenology, The Hague, Martinus Nijhoff, 1973, pp. 306-327, p. 306 , nota 1)

31 O tipo de «completude» que está aqui em causa é, como estamos a ver, aquele a que os matemáticos chamam semântico, ou seja, aquele segundo o qual todas as fórmulas válidas de um determinado domínio de objectos se podem demonstrar a partir de um sistema de axiomas. (Cf. a nossa nota n. ${ }^{\circ}$ 17) Sobre este assunto, cf. Dieter Lohmar, Edmund Husserls "Formale und transzendentale Logik», Darmstadt, Wissenschaftliche Buchgesellschaft, 2000, pp. 81-82.

32 Cf. Husserl, Erster Philosophie, I, Husserliana, Band VII, p. 26. 